\title{
Normative data for lung function and exhaled nitric oxide in unsedated
} healthy infants

\author{
O. Fuchs*, , P. Latzin*,\#, C. Thamrin*, G. Stern*, P. Frischknecht*, F. Singer*, \\ E. Kieninger*, E. Proietti*, T. Riedel ${ }^{\star}$ and U. Frey*,
}

ABSTRACT: Despite association with lung growth and long-term respiratory morbidity, there is a lack of normative lung function data for unsedated infants conforming to latest European Respiratory Society/American Thoracic Society standards.

Lung function was measured using an ultrasonic flow meter in 342 unsedated, healthy, termborn infants at a mean \pm SD age of $5.1 \pm 0.8$ weeks during natural sleep according to the latest standards. Tidal breathing flow-volume loops (TBFVL) and exhaled nitric oxide (eNO) measurements were obtained from 100 regular breaths. We aimed for three acceptable measurements for multiple-breath washout and 5-10 acceptable interruption resistance (Rint) measurements.

Acceptable measurements were obtained in $\leqslant 285$ infants with high variability. Mean values were $7.48 \mathrm{~mL} \cdot \mathrm{kg}^{-1}\left(95 \%\right.$ limits of agreement $\left.4.95-10.0 \mathrm{~mL} \cdot \mathrm{kg}^{-1}\right)$ for tidal volume, $14.3 \mathrm{ppb}(2.6-$ $26.1 \mathrm{ppb})$ for eNO, $23.9 \mathrm{~mL} \cdot \mathrm{kg}^{-1}\left(16.0-31.8 \mathrm{~mL} \cdot \mathrm{kg}^{-1}\right)$ for functional residual capacity, 6.75 (5.637.87) for lung clearance index and $3.78 \mathrm{kPa} \cdot \mathrm{s} \cdot \mathrm{L}^{-1}\left(1.14-6.42 \mathrm{kPa} \cdot \mathrm{s} \cdot \mathrm{L}^{-1}\right)$ for Rint. In males, TBFVL outcomes were associated with anthropometric parameters and in females, with maternal smoking during pregnancy, maternal asthma and Caesarean section.

This large normative data set in unsedated infants offers reference values for future research and particularly for studies where sedation may put infants at risk. Furthermore, it highlights the impact of maternal and environmental risk factors on neonatal lung function.

KEYWORDS: Exhaled nitric oxide, functional residual capacity, interrupter resistance, neonates, pulmonary function test, reference values

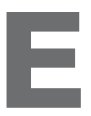
arly lung development is important for long-term lung growth [1, 2]. So-called tracking of lung function has been found in retrospective chart and prospective cohort studies $[3,4]$. Early lung function changes may affect longterm respiratory morbidity and even mortality [5-7], necessitating longitudinal studies. Although lung function in infants is frequently measured in various ongoing cohort studies, there is still a lack of contemporary and equipment-specific normative data to identify reduced lung function, define disease states and assess lung growth [8].

Technical developments, improved understanding and increased survival of pre-term infants have facilitated a more widespread use of infant lung function measurements. However, due to the time-consuming and costly nature of rigorous lung function measurements, especially in nonsedated infants, reference values exist only for small cohorts of healthy infants. Moreover, especially for multiple breath washout (MBW) tests, most lung function equipment is custom-built, limiting comparability among centres despite the availability of standards by the European Respiratory Society (ERS) and the American Thoracic Society (ATS) [9-11]. To further complicate matters, different centres tend to prefer and present data from different techniques.

Therefore, we aim to present normative data from tidal breathing flow-volume loops (TBFVL), exhaled nitric oxide (eNO), MBW and interrupter resistance (Rint) measurements in unselected infants of a narrow age range using standardised equipment and collected without sedation.
AFFLLIATIONS

*Division of Respiratory Medicine, Dept of Paediatrics,

-Division of Paediatric Intensive Care Medicine, Dept of Paediatrics, Inselspital and University of Berne, \#Institute of Social and Preventive Medicine, University of Berne, Berne, and

+University Children's Hospital (UKBB), University of Basel, Basel, Switzerland.

CORRESPONDENCE

U. Frey

University Children's Hospital

(UKBB)

Spitalstrasse 33

4056 Basel

Switzerland

E-mail: urs.frey@ukbb.ch

Received:

Aug 052010

Accepted after revision:

Oct 252010

First published online:

Nov 252010 
Subsets of the lung function data have been previously published [12-21]. The aim of this article is to summarise cohort data and to present a comprehensive set of reference values for all measured lung function parameters as normative and reference values in a white, Middle European population of the given age. Furthermore, we investigated how lung function in early life is related to anthropometric, perinatal and maternal, as well as environmental, factors.

\section{METHODS}

\section{Subjects}

Data were collected from an ongoing prospective birth cohort of unselected, healthy neonates recruited antenatally since 1999 in the region of Berne, Switzerland: the Bern Infant Lung Development (BILD) cohort [16]. The following inclusion criteria applied: white ethnicity, term delivery ( $\geqslant 37$ weeks), and no known major birth defects or perinatal disease of the newborn. Known and potential confounders of lung function (demographic data, sociodemographic status, smoke exposure and parental atopic disease, being defined as either atopic dermatitis, atopic rhinitis or atopic asthma in either parent) were assessed by interviews using standardised questionnaires $[22,23]$. In addition, a skin prick test including six common allergens (dog dander, cat dander, Dermatophagoides pteronyssinus, mixed tree pollens, mixed grass pollens and Alternaria tenuis; Allergomed AG, Therwil, Switzerland) was performed in a subgroup of mothers. We validated antenatal maternal smoking history by cotinine levels in the first urine of the newborn (gas-liquid chromatography; IST, Lausanne, Switzerland). The Bernese Cantonal Ethics Research Committee (Berne, Switzerland) approved the study protocol and written parental consent was obtained at enrolment.

\section{Lung function}

Lung function was measured in unsedated neonates during behaviourally defined quiet natural sleep [24]. Measurements followed regular feeding of the infants, usually resulting in natural sleep in this age group. They were performed supine with the head midline via an infant mask (for TBFVL and MBW; size 1; Homedica AG, Huenenberg, Switzerland), according to the ERS/ATS standards of infant lung function testing [9-11] and eNO measurement [25]. Flow was measured using an ultrasonic flow meter (Spiroson ${ }^{\circledR}$; EcoMedics AG, Duernten, Switzerland). Data were included if no apparent volume drift was present, defined as a change of $<2 \mathrm{~mL} \cdot \mathrm{s}^{-1}$. Measurements were always performed in the same order: 10 min tidal breathing followed by three acceptable MBW measurements when possible and, lastly, interrupter measurements if the child was still asleep. None of the infants had ever been given inhaled pulmonary medication.

\section{Tidal breathing}

For analysis, we used the first 100 regular breaths of tidal breathing during non-rapid eye movement (non-REM) sleep from the total recording over $10 \mathrm{~min}$, and excluded the first 2030 breaths after mask placement to allow for adjustment of breathing pattern. In addition, sighs, together with 10 breaths before and after a sigh, were excluded to reduce noise [13]. Mean tidal breathing parameters of flow, volume and flowvolume loop were then calculated according to ERS/ATS standards [11]. Main outcome parameters were tidal volume
$(V \mathrm{~T})$, minute ventilation $\left(V^{\prime} \mathrm{E}=V \mathrm{~T} \times\right.$ respiratory rate), mean tidal inspiratory and expiratory flow, and time to peak tidal expiratory flow ( $t \mathrm{PTEF}$ )/expiratory time ( $t \mathrm{E})$ ratio to describe the shape of the TBFVL $[11,26]$.

\section{Nitric oxide}

Simultaneous to TBFVL recording, eNO was measured online with a rapid-response chemoluminescence analyser (CLD 77 AM; EcoMedics AG, Duernten, Switzerland). Contamination of eNO by ambient nitric oxide (NO) was avoided by using NO-free air for inspiration. We measured eNO breath-bybreath during the third quartile of expiration and calculated mean eNO over 100 breaths, correcting for expiratory flow as described previously [16, 27]. Main outcome parameters were $\mathrm{eNO}$ and $\mathrm{NO}$ output $(\mathrm{eNO}$ concentration $\times$ corresponding expiratory flow $\left.\left(V^{\prime} \mathrm{NO}\right)\right)$.

\section{Multiple breath washout}

Lung volume and ventilation inhomogeneity (VI) were determined using $\mathrm{MBW}$ technique by ultrasonic flowmeter with $4 \%$ sulphur hexafluoride $\left(\mathrm{SF}_{6}\right)$ as described previously [18]. Main outcomes were functional residual capacity (FRC) at airway opening (FRCao), FRCao per body weight and lung clearance index (LCI; cumulative expired volume/FRCao). Data were excluded in the case of REM sleep state or the infant waking up during the MBW measurement, as well as occurrence of sighs during wash-in or $\leqslant 10$ breaths after start of wash-out and if extrapolated FRC was $>10 \%$ of FRC at midsensor point (FRCmid), if breath baseline was $>10 \%$ FRCmid, if the tracer gas fraction was $>1 \%$ at the end of washout, if the end-inspiratory molar mass in the respective MBW measurement trace was not constant, and if there was no quiet tidal breathing prior to wash-in.

\section{Interrupter technique}

Interrupter measurements were made with a rigid face mask (size 1; Silkomed Model 852713; Jaeger Viasys, Hoechberg, Germany) lined with putty to ensure a leak-free seal and to reduce dead space. Following stable TBFVL recordings, a series of interruptions were made once every three to six breaths. No guidelines exist at present for interrupter measurements in infants. Thus, early in the study, infants were studied with an occlusion time of $500 \mathrm{~ms}$; however, during longer measurements, it was noted that Rint tended to increase over time. Thus, the occlusion time was later shortened to $200 \mathrm{~ms}$ to attempt to ensure that normal breathing patterns were not altered. Otherwise, measurements were performed as described previously [28]. Data were further excluded if less than five acceptable interruptions were recorded [29]. Summary Rint data were determined from the first $5-10$ acceptable interruptions per measurement. Rint was calculated using the linear back-extrapolation method, applied to the trace of pressure at airway opening $(P a)$ between 30 and $70 \mathrm{~ms}$ post-interruption [28]. Repeatability was assessed in 22 infants in whom more than one measurement was made.

\section{Statistical analysis}

Descriptive statistics and regression analyses were performed using STATA 10 for Windows (STATA Corporation, College Station, TX, USA). We assessed the influence of known confounders (sex, post-conception age, weight and length, as well 
as study weight and length, and maternal smoking during pregnancy) and potential confounders (maternal asthma and atopy, positive maternal skin prick test, paternal asthma and Caesarean section) by performing uni- and multivariable regression analyses. For consistency of reporting, all confounders were included in univariable regression analyses of each outcome. Multivariable models were fitted with parameters that were significantly associated with outcomes in the univariable models, and which remained significantly associated after a backward stepwise exclusion strategy of dropping the explanatory variable with the highest $p$-value until only significant associations were left in the final model. A p-value $<0.05$ was considered significant. Due to significant associations with sex, TBFVL analyses were further stratified by sex. Final multiple regression models were used to build sex-specific (TBFVL outcomes) or unisex (for all other outcomes) regression equations containing predictors or determinants of each outcome and to calculate residual standard deviations if significant associations with analysed explanatory variables could be found.

\section{RESULTS}

Between 1999 and 2010, the study enrolled 365 eligible infants, of whom 342 presented for lung function measurements at $\sim 5$ weeks post-natal age. Of these, technically acceptable data with high variability were obtained from up to 286 infants, shown in figure 1 together with numbers of infants not presented to lung function tests, and criteria for general and specific exclusion for each measurement technique. Table 1 presents anthropometric, demographic and socioeconomic characteristics, and distribution of known and possible confounders among all study participants that presented for lung function and eNO measurement at the age of 5 weeks before application of general exclusion criteria prior to data analysis. We did not find any differences between infants for whom measurements were performed compared to those that were not presented for measurements or generally excluded (data not shown), except for a trend towards a higher proportion of mothers who smoked during pregnancy among infants that did not present for measurements ( 25.0 versus $10.8 \%$; $p=0.055)$.
Not presented for lung function or general exclusion

$$
n=23
$$

Not presented for lung function and eNO measurements $\#$ $n=8$ No further interest in study despite initial recruitment $n=1$ Parents moving away after recruitment

$\mathrm{n}=11$ No interest in lung function test but still in cohort study

n=3 Infant sick, no auxiliary date

\section{$\mathrm{n}=46$}

General exclusion from all measurements/data analyses: $n=7$ Insufficient or REM sleep

$n=10$ Excluded for postnatal age of 48 days or higher $n=5$ Respiratory tract infection $\leq 2$ weeks prior to measurement

$\mathrm{n}=2$ Chronic disease diagnosed after birth (noneligibility) $n=4$ Gestational age $<37$ weeks (presented for lung function test despite noneligibility

$\mathrm{n}=18$ Nonwhite ethnicity (presented for lung function test despite noneligibility ${ }^{+}$

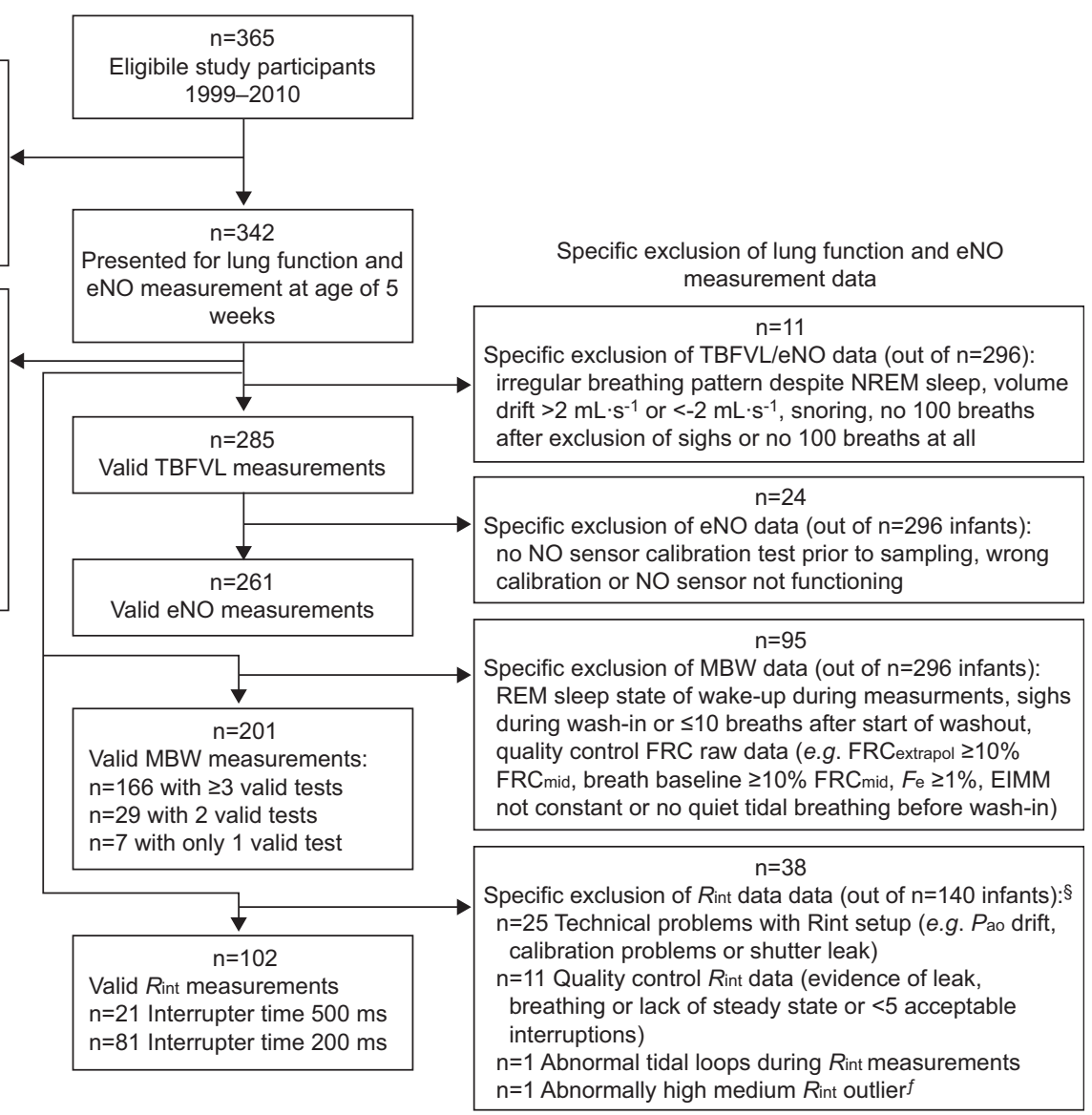

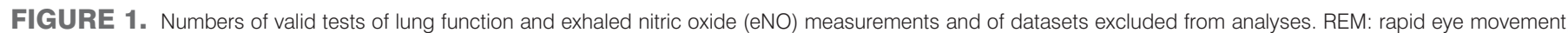

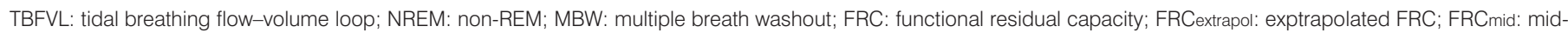

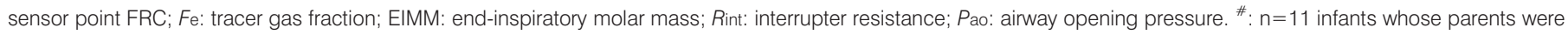

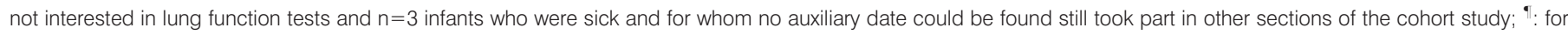

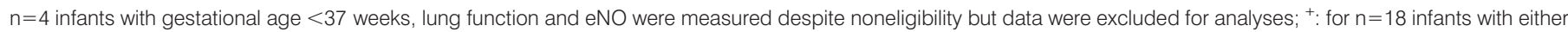

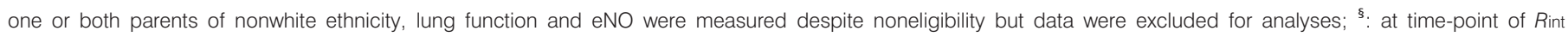

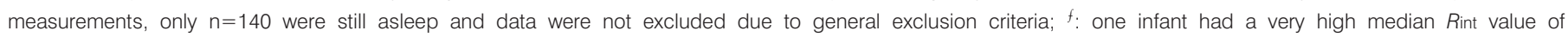
$14.37 \pm 3.61 \mathrm{kPa} \cdot \mathrm{s} \cdot \mathrm{L}^{-1}$ and was excluded as outlier. 
TABLE 1 Anthropometric, demographic and socioeconomic characteristics, and distribution of known and possible confounders among study participants presented for lung function ${ }^{\#}$

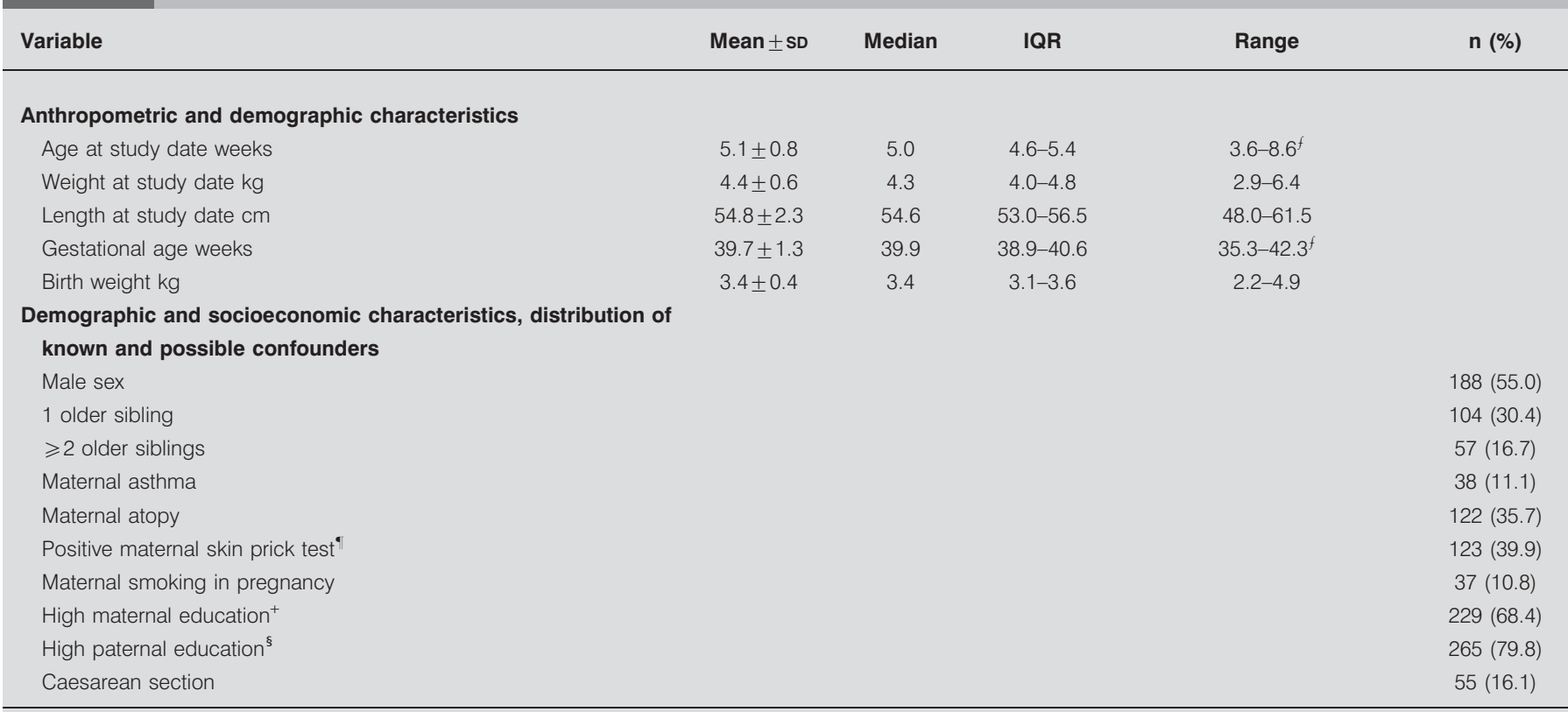

IQR: interquartile range. ${ }^{*}: \mathrm{n}=342 ;{ }^{\bullet}$ : missing data on $n=34$; data available for $n=308$ mothers; ${ }^{+}:$missing data on $n=7$; data available for $n=335$ mothers; ${ }^{\S}$ : missing data on $n=10$; data available for $n=332$ fathers; ${ }^{f}$ : all data presented here refer to study participants presented for lung function tests before application of general exclusion criteria prior to data analysis (fig. 1).

None of the presented outcomes showed significant deviation from the normal distribution.

\section{Tidal breathing}

As we found significant associations with sex for most of the studied TBFVL outcomes (see online supplementary tables E.3 and E.4), analyses were also stratified by sex. Normative TBFVL data for infants irrespective of sex are given in table 2; data for females and males are shown separately in online supplementary tables E.1 and E.2, respectively. Median intrasubject coefficiencts of variation $(\mathrm{CVs})$ demonstrated variability for each outcome, such as $7.5 \%$ (interquartile range (IQR)
6.1-10.1\%) for $V^{\prime} \mathrm{E}$ and up to $23.8 \%$ (IQR 20.2-28.4\%) for $t \mathrm{PTEF} /$ $t \mathrm{E}$, irrespective of sex. Associations of known and possible confounders with tidal breathing parameters are shown in online supplementary tables E.3 and E.4 without stratification and in tables E.5 and E.8 after stratification for sex. Whereas TBFVL outcomes were only significantly associated with anthropometric parameters in males, in females, we also found associations with maternal smoking during pregnancy, maternal asthma and Caesarean section. Sex-specific regression equations containing predictors or determinants of TBFVL measurements are given in online supplementary table E.9.

\section{TABLE 2 Normative lung function values from acceptable tidal breathing measurements for 285 infants at 5 weeks of age without} stratification for sex

\begin{tabular}{|c|c|c|c|c|}
\hline Tidal breathing parameter & Mean $\pm S D$ & $95 \%$ limits of agreement ${ }^{\#}$ & Range & Median (IQR) intrasubject CV $\%$ \\
\hline$V^{\prime} E \mathrm{~mL} \cdot \mathrm{min}^{-1}$ & $1420 \pm 277$ & 876-1960 & $733-2370$ & $7.5(6.1-10.1)$ \\
\hline$V^{\prime} \mathrm{E} /$ body weight $\mathrm{mL} \cdot \mathrm{min}^{-1} \cdot \mathrm{kg}^{-1}$ & $328 \pm 65$ & $201-455$ & $174-613$ & \\
\hline Respiratory rate breaths $\cdot \mathrm{min}^{-1}$ & $45.2 \pm 10.5$ & $24.6-65.7$ & $24.7-78.7$ & $9.1(7.4-11.3)$ \\
\hline Tidal volume $\mathrm{mL}$ & $32.4 \pm 5.5$ & $21.7-43.1$ & $21.0-51.1$ & $8.6(7.1-10.8)$ \\
\hline Tidal volume/body weight $\mathrm{mL} \cdot \mathrm{kg}^{-1}$ & $7.48 \pm 1.29$ & $4.95-10.0$ & $4.28-11.8$ & \\
\hline tPTEF/tE \% & $34.8 \pm 10.7$ & $13.8-55.9$ & $14.2-73.3$ & $23.8(20.2-28.4)$ \\
\hline
\end{tabular}

CV: coefficient of variation; IQR: interquartile range; $V^{\prime} E$ : minute ventilation; tPTEF: time to peak tidal expiratory flow; $t E$ : expiratory time. ${ }^{\#}: 95 \%$ limits of agreement calculated as mean $\pm 1.96 \times \mathrm{SD}^{\prime}{ }^{\prime}$ : intrasubject CVs were calculated as the ratio of SD for each outcome parameter over each mean value of outcome parameter per study participant; due to positively skewed distributions, the table presents the overall median (IQR) for all intrasubject CVs. 


\section{Nitric oxide}

Normative data for eNO measurements are shown in table 3. Median intrasubject CV was relatively large both for eNO with 10.3\% (IQR 6.4-15.7\%) and for $V^{\prime}$ NO with $12.4 \%$ (IQR $8.9-$ $18.1 \%)$. Associations of known and possible confounders with eNO and $V^{\prime} \mathrm{NO}$ are shown in online supplementary table E.10. Only $V^{\prime}$ E stayed significantly associated with both eNO and $V^{\prime} \mathrm{NO}$ in the multivariable model, whereas eNO was also associated with body length at study date and $V^{\prime}$ NO with body weight at study date in the final models. Online supplementary table E.13 shows unisex regression equations containing predictors or determinants of eNO measurements.

\section{Multiple breath washout}

Normative data for MBW measurements are presented in table 3, unisex regression equations containing predictors or determinants of MBW measurements are shown in online supplementary table E.13. MBW data showed relatively small intrasubject CVs, with a median of $6.3 \%$ (IQR $4.4-8.3 \%$ ) for FRCao and 5.8\% (IQR 3.6-8.0\%) for LCI. Associations of known and possible confounders with FRCao and LCI are shown in online supplementary table E.11. FRCao was associated with age at study date and birth length in the final multivariable model. For LCI, no associations were found.

\section{Interrupter technique}

With the mean difference between Rint measurements using the two occlusion times being significant (online supplementary table E.12), all analyses were corrected for occlusion time. Normative Rint data are presented in table 3 and show high variability, with a median intrasubject CV of $19.3 \%$ (IQR $14.7-$ $25.3 \%$ ) irrespective of occlusion time. Rint was only significantly associated with study age in the multivariable analysis after correction for occlusion time (online supplementary table E.12). During the assessment of median Rint repeatability, the mean difference between two successive measurements was $0.14 \mathrm{kPa} \cdot \mathrm{s} \cdot \mathrm{L}^{-1}\left(95 \% \mathrm{CI}-0.38-0.65 \mathrm{kPa} \cdot \mathrm{s} \cdot \mathrm{L}^{-1} ; \mathrm{p}=0.586\right)$, with limits of agreement of $-2.12-2.39 \mathrm{kPa} \cdot \mathrm{s} \cdot \mathrm{L}^{-1}(2 \times \mathrm{SD})$, and without evidence of systematic bias. Online supplementary table E.13 shows unisex regression equations containing predictors or determinants of Rint measurements in infants.

\section{DISCUSSION}

\section{Summary}

To the authors' knowledge, this is the first study in which reference values for TBFVL, eNO, MBW and Rint measurements, collected during quiet natural sleep without sedation in a prospective and homogenous cohort of healthy, unselected and term-born infants at the post-natal age of 5 weeks, are presented. Since we assessed the data prospectively, it was possible to maintain the standards of measurements in a strictly consistent manner unchanged over 10 yrs of work. We show, in a large number of subjects, that lung function tests without sedation are possible in the majority of infants in the first 2 months of post-natal life. The results obtained in healthy individuals display a high variability, with implications for their use as normative data. In addition, we found sex-specific associations of TBFVL outcomes with gestational age, birth length, maternal smoking during pregnancy, maternal asthma but not atopy, and Caesarean section in females, whereas for males, significant associations were only found for anthropometric factors. The differences between sexes are scientifically interesting and may have their role on a population basis. But given the high within- and between-subject variability for most outcomes, absolute differences between girls and boys are unlikely to be of any clinical significance in individuals.

\begin{tabular}{|c|c|c|c|c|c|}
\hline & $\begin{array}{l}\text { Participants with valid } \\
\text { measurements } n\end{array}$ & Mean \pm SD & $\begin{array}{l}\text { 95\% limits of } \\
\text { agreement }{ }^{\#}\end{array}$ & Range & $\begin{array}{c}\text { Median (IQR) } \\
\text { intrasubject CV }\end{array}$ \\
\hline Inflammatory markers ${ }^{+}$ & 261 & & & & \\
\hline eNO ppb & & $14.3 \pm 6.0$ & $2.57-26.1$ & $0.9-35.0$ & $10.3(6.4-15.7)$ \\
\hline FRCao $\mathrm{mL}$ & & $102 \pm 16$ & $70.0-134$ & $65.8-145$ & $6.3(4.4-8.3)$ \\
\hline FRCao/body weight $\mathrm{mL} \cdot \mathrm{kg}^{-1}$ & & $23.9 \pm 4.0$ & $16.0-31.8$ & $13.0-35.8$ & \\
\hline $\mathrm{LCl}$ & & $6.75 \pm 0.57$ & $5.63-7.87$ & $5.51-8.62$ & $5.8(3.6-8.0)$ \\
\hline $\operatorname{Rint}^{f, \# \#} \mathbf{k P a} \cdot \mathbf{S} \cdot \mathbf{L}^{-1}$ & 102 & & & & \\
\hline Occlusion time $500 \mathrm{~ms}$ & 21 & $4.31 \pm 1.34$ & $1.68-6.94$ & $2.69-7.56$ & $16.6(10.4-20.2)$ \\
\hline
\end{tabular}

CV: coefficient of variation; IQR: interquartile range; FRCao: functional residual capacity at airway opening; LCl: lung clearance index. *: 95\% limits of agreement calculated as mean $\pm 1.96 \times \mathrm{SD}$; ": intrasubject CVs were calculated as the ratio of SD for each outcome parameter over each mean value of outcome parameter per study participant; as all presented outcomes except for $\mathrm{LCl}$, for which there was a negatively skewed distribution, showed positively skewed distributions for intrasubject CVs, the table presents the overall median and interquartile range for all intrasubject $\mathrm{CVs}^{+}{ }^{+}$: proportion of male infants for all 261 measurements $55.9 \%$; : $\mathrm{n}=105$ acceptable MBW measurements

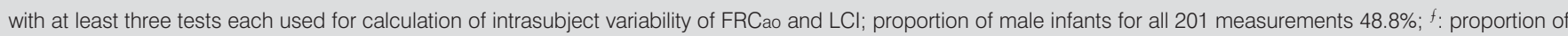

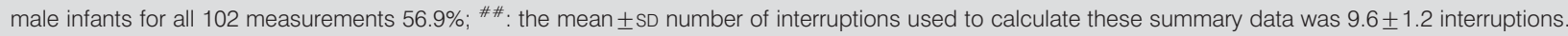




\section{Significance and strengths of the study}

These equipment-specific normative data provide the basis to address questions for clinical and epidemiological research at the population level, such as lung function tracking or discrimination between disease groups. But before it may also be of use at the individual level in the future by overcoming the lack of reference values for clinical assessments, further work on interpretation of the large within- and betweensubject variability is clearly warranted and our work may in addition help to prevent over interpretation of clinical findings and "abnormalities" on the individual level at this time point.

All data were collected in the same order and with the same equipment in a cohort that has a number of methodological strengths, especially with regard to the costly and timeconsuming nature of lung function measurements in unsedated infants. We applied extensive quality control during data collection. Tidal breathing and eNO measurements adhere to latest standards from the ERS and ATS [9-11]. Because we aimed to present reference values, to some extent, an even more conservative approach was adopted, such as for the analysis of tidal breathing: for better accuracy we used 100 instead of 30 breaths as currently recommended [11], and excluded sighs together with 10 breaths before and after a sigh to reduce noise [13]. This approach does not affect the recommendations to use a total 30 breaths for analysis in daily practice, as long as these are not in vicinity, i.e. $\leqslant 10$ breaths before and after a sigh, because we have not found significant differences for TBFVL outcomes from measurements with 30 or 100 breaths but without sighs. MBW and Rint measurements were also performed according to the most recent validated recommendations [18, 29]. Also because we aimed to present reference values, extensive quality control included properly calibrated devices for anthropometric measures. Thus, similar careful approaches for calibration, measurement and analyses for all measured outcomes are required if these normative data are to be applicable in other settings.

\section{Limitations and open questions}

As post-natal time represents a period of rapid lung growth, measuring lung function during such a narrow age range provides a snapshot of only a limited time period. However, it also enables the quantification of normative values for this specific age as well as their high variability.

For the analysis of associations of known and possible confounders with measured outcomes, we assumed linear relationships, which might be an oversimplification of their biological role. This is especially true for the computation of regression equations, where we, given the narrow age range, have not applied further advanced methods widely used to construct reference charts over wide age ranges, such as an extension of the LMS (lambda, mu, sigma) method [30]. Due to the narrow age range, the equations should be used with caution and must not be extrapolated beyond measures in unsedated white infants in the first 8 weeks of life. As ethnicity has also been shown to play a role in tidal breathing patterns of young infants [31], we have applied stringent adherence to exclusion criteria including ethnicity. Thus, this set of normative data and regression equations is restricted to a white Middle European ethnicity of the assessed age range.
In addition, we cannot exclude the possibility of bias towards a well-educated, middle-class population. However, social class so far has neither been a risk factor nor a risk modifier in our past analyses, e.g. assessing the effect of traffic-related air pollution on lung function in infants [32].

\section{Comparison with other studies}

\section{Tidal breathing}

Data on lung function parameters in unsedated healthy infants using the same technique as our group are scarce. Comparable data are available from pneumotachography studies, such as a study by LØDRUP-CARLSEN et al. [33] studying 802 awake healthy infants directly after birth (e.g. mean $V$ T $24.8 \mathrm{~mL}$ and mean $\mathrm{tPTEF} / \mathrm{tE} 32.0 \%$ ) and one by STOCKS et al. [34] assessing lung function in 23 full-term unsedated infants of equivalent age (mean VT $36.1 \mathrm{~mL}$ and mean $\mathrm{tPTEF} / \mathrm{tE} 32.5 \%$ ). Our data also compares favourably with studies assessing the $t \mathrm{PTEF} / t \mathrm{E}$, supporting the idea of a slowly decreasing $t \mathrm{PTEF} / t \mathrm{E}$ during the first year of life, although these studies use several techniques with and without sedation over a wide age range [35].

We found a significant association of maternal asthma with tidal inspiratory flow in females, but otherwise no further effect of parental atopy or positive maternal skin prick test on lung function in our infants. Here, comparable data are also scarce, but our data are partly in contrast with other studies, mostly undertaken in high risk infants, where positive associations with parental atopy and subnormal lung function in infants could be found [36].

Several studies have reported reduced lung function in infants whose mothers smoked during pregnancy [37-39]. We were not able to replicate this finding without stratification for sex. This is most probably due to our low prevalence of $\sim 10 \%$ of smoking mothers during pregnancy, validated by cotinine measurements in the urine. However, we found an effect of maternal smoking during pregnancy for several tidal breathing parameters in females. This can be interpreted as worsened lung function with higher respiratory rate, lower $V \mathrm{~T}$ and a higher $t \mathrm{PTEF} / \mathrm{tE}$, demonstrating an adaptive response to altered lung mechanics in unsedated infants. Sex differences with regard to the effect of smoking on lung function are known in older children and in sedated infants $[40,41]$ but, to the authors' knowledge, not in unsedated infants to date. This is despite intense research, especially on the effect of genetic risk factors on the impact of prenatal environmental tobacco smoke exposure on lung function in infants, for which these results would be highly relevant [42].

In addition, we present a small but significant influence of Caesarean section on respiratory rate in our final model for females. This is in contrast to a study where no effect was found in 24 awake healthy infants at the age of 2-4 days for $t \mathrm{PTEF} / \mathrm{tE}$ after this being initially decreased on day 1 [43]. The differences may be due to different measurement techniques and numbers, and especially the different age at measurement. Current knowledge relates respiratory morbidity immediately after birth in children born per Caesarean section partly to the failure to clear fetal lung fluid. In contrast to immediate effects, such as transient tachypnoea of the newborn and surfactant deficiency, long-term physiological effects are so far unknown [44]. 


\section{Nitric oxide}

eNO plays an important role as a measure of airway inflammation. Past findings from subsets of this cohort have shown eNO to precede respiratory symptoms in newborns of atopic or smoking mothers [16] and to be elevated in infants exposed to traffic-related air pollution $\left(0.98 \mathrm{ppb}\right.$ per $\left.\mu \mathrm{g} \cdot \mathrm{m}^{-3} \mathrm{NO}_{2}\right)$ [32]. To date, eNO has been measured using both single- and multiplebreath techniques, each with their own methodological issues [45]. There are only sparse eNO data available from unselected, healthy and unsedated infants collected using a common technique and adhering to standards. Our data are lower than those collected using a single-breath method in older healthy infants (mean $18.8 \mathrm{ppb}$ ) [46], and with a median of $14 \mathrm{ppb}$ (IQR 10.7-17.4 ppb), also lower than those collected in a high-risk cohort of infants at comparable age using the offline method with a median $16 \mathrm{ppb}$ (IQR 12-22 ppb) [47]. Further influencing factors, such as ambient $\mathrm{NO}$, but also food, beverage or medication intake, can be neglected in our study population of healthy and breast-fed infants. Breast-feeding has been shown to have no effect on eNO levels in infants [48]. As all infants with respiratory tract infection were excluded, this influence on eNO is also negligible. Except for anthropometric factors, we could not find further associations with eNO or $V^{\prime}$ NO levels, including family history of atopic disease in the whole cohort.

In older children, oral eNO has been shown to be significantly lower than mixed (oral and nasal) eNO (geometric means 4.5 and $10.5 \mathrm{ppb}$, respectively) [48]. The same is true for lower airway and nasal levels of eNO [49]. However, at the age of our study participants, paranasal sinuses have only rarely developed, if at all. For infants slightly older than our study participants, there has not been any difference between strictly oral or nasal eNO [50]. Although mixed eNO has been shown in infants to differentiate health from a variety of airway diseases $[27,50,51]$, this must be considered before using our normative values as reference.

\section{Multiple breath washout}

Gas mixing techniques, such as MBW, primarily reflect small airways and effect of disease or other factors on changes in lung size and the degree of VI [52]. Also, here, normative data for healthy unsedated infants are scarce. In addition to previous data from subsets of our cohort [17, 18, 20], HULSKAMP et al. [53] published normative values from a multicentre study also including 64 healthy infants of mixed ethnicity and with a mean post-gestational age of 4 weeks; thus, they were slightly younger than our study participants, but collected with the same technique in unsedated infants during quiet natural sleep, using similar quality control measures [18]. Compared to our data, they found slightly higher mean $\pm S D$ values for LCI $(7.17 \pm 0.45)$ and lower ones for FRCao/body weight (18.4 \pm $\left.3.6 \mathrm{~mL} \cdot \mathrm{kg}^{-1}\right)$. As HULSKAMP et al. [53] performed measurements in younger infants from a multicentre study with mixed ethnicity and appreciable intercentre differences, this is most probably due to the different populations measured. Also, although the same technique and identical quality control and acceptability criteria were used, small differences due to different hard- and software settings cannot be excluded.

\section{Interrupter technique}

Comparable data from infants are again scarce. The median Rint value from this study was higher than that obtained by
CHAVASSE et al. [54] in healthy sedated infants with a mean \pm SD of $2.94 \pm 0.68 \mathrm{kPa} \cdot \mathrm{L} \cdot \mathrm{s}^{-1}$, in whom upper airway mechanics are likely more relaxed and control of breathing different. Furthermore, CHAVASSE et al. [54] used a shorter occlusion time of $100 \mathrm{~ms}$. Our study compares favourably with the calculated Rint from reference equations obtained from infants and children from 3 weeks to 15 yrs of age [55].

It is difficult to determine the reason for the difference we saw between occlusion times. While the effect of various occlusion parameters on Rint has been investigated, there have been no studies examining the effect of interruption time. One possible explanation is the alteration of breathing mechanics with longer interruption times, affecting control of breathing, and slightly increased humidity or hypercapnic conditions in the airways due to increased extent of flow occlusion. In addition to the increased Rint with increased interruption time, we observed that Rint also increased slowly with time during longer interrupter measurements (data not shown). Alternatively, the longer interruption time allowed for more muscle relaxation and pressure equilibration, although this can be discounted since evidence of a steady state in $P$ ao was seen in all included measurements. Recommendations for infant Rint measurement also covering interruption time are clearly warranted, and in the paucity of studies examining these issues [28], it appears that a shorter interruption time would reduce the risk of altered breathing mechanics and increased resistance.

\section{Conclusions}

Despite their time-consuming and costly nature, lung function measurements in unsedated infants shortly after birth are feasible. This enables determination of lung growth and influencing factors during the vulnerable phase of lung development before birth and the first few weeks of life. These have been shown to be crucial, also with regard to later pulmonary morbidity. The presented normative data adhere to the latest standards and were collected under extensive quality control. The sex-specific associations of covariates with lung function provide the basis to address research questions at the population level, such as the tracking of lung function, discrimination between disease groups, and the effect of influencing factors on lung function and airway inflammation without the influence of sedation.

At the individual level, our data also address the lack of reference values for the clinical assessment of lung function, one of the major barriers to its routine implementation. Collecting reference values in unsedated infants is particularly needed for studies in infants suffering from lung disease in whom sedation may put the individual infant at risk. The high within- and between-subject variability of normative values in healthy term infants may help explain why there is still no convincing evidence for the clinical utility of infant lung function techniques in the individual clinical decision making process. However, our data may provide the basis for future studies addressing the issue of interpreting the large withinsubject and intrasubject variability. They may, in addition, prevent current mis- or over interpretation of clinical findings at the individual level and may help to prepare the ground for using infant lung function in clinical routine, such as to assess effects of clinical interventions. 


\section{SUPPORT STATEMENT}

This work was supported by the Swiss National Science Foundation (grant numbers 32003B_124654/1 and 3200-B0-12099 to O. Fuchs, 3200-B0-12099 and 3200-052197.97/1 to P. Latzin, and 32003B_124654/1, 3200-B0-12099, 3200-052197.97/1, 3200-052197.97/2, 3200-068025 and 32-68025.02 to U. Frey), the European Respiratory Society (Long-Term Research Fellowship 675 to O. Fuchs) and the Austrian, German and Swiss Paediatric Respiratory Society (Training Scholarship 2009 to O. Fuchs).

\section{STATEMENT OF INTEREST}

Statements of interest for P. Latzin and U. Frey can be found at www. erj.ersjournals.com/site/misc/statements.xhtml

\section{ACKNOWLEDGEMENTS}

The authors thank all study participants and their families for participating in the study and the staff of the four major maternity hospitals in the Bernese region (Klinik Engeried-Sonnenhof, Lindenhofspital, SalemSpital and Universitätsklinik für Frauenheilkunde Bern) for support and recruitment. They also thank D. Baldwin (Neonatal Clinical Care Unit, King Edward Memorial Hospital, Perth, Australia), G. Hall (Telethon Institute for Child Health Research, Princess Margaret Hospital for Children, and School of Paediatrics and Child Health, University of Western Australia, Perth), G. Hutten (Department of Paediatric Pulmonology, Emma Children's Hospital, University of Amsterdam, Amsterdam, the Netherlands), M. Cernelc (Kapiolani Medical Center for Women and Children, University of Hawaii, Honolulu, HI, USA), N. Petrus (Department of Paediatric Pulmonology, Emma Children's Hospital), M. Kyburz (Stadtspital Triemli, Zürich, Switzerland), H. Roiha (formerly Division of Respiratory Medicine, Dept of Paediatrics, Inselspital and University of Berne, Berne, Switzerland) and C. Casaulta (Division of Respiratory Medicine, Department of Paediatrics, Inselspital and University of Berne) for valuable assistance in performing measurements. Moreover, they especially thank the study nurses M. Graf, B. Hofer, and C. Becher, as well as the lung function assistants G. Wirz and S. Luescher (all Division of Respiratory Medicine, Dept of Paediatrics, Inselspital and University of Berne) for their truly invaluable assistance and support, as well as L. Sauteur (formerly Division of Respiratory Medicine, Department of Paediatrics, Inselspital and University of Berne) for her help in the analysis of the measurements.

\section{REFERENCES}

1 Silverman M, Kuehni CE. Early lung development and COPD. Lancet 2007; 370: 717-719.

2 Checkley W, West KP Jr, Wise RA, et al. Maternal vitamin A supplementation and lung function in offspring. $N$ Engl J Med 2010; 362: 1784-1794.

3 Barker DJ, Godfrey KM, Fall C, et al. Relation of birth weight and childhood respiratory infection to adult lung function and death from chronic obstructive airways disease. BMJ 1991; 303: 671-675.

4 Stern DA, Morgan WJ, Wright AL, et al. Poor airway function in early infancy and lung function by age 22 years: a non-selective longitudinal cohort study. Lancet 2007; 370: 758-764.

5 Martinez FD. Links between pediatric and adult asthma. J Allergy Clin Immunol 2001; 107: Suppl., S449-S455.

6 Johnston ID, Strachan DP, Anderson HR. Effect of pneumonia and whooping cough in childhood on adult lung function. $N$ Engl J Med 1998; 338: 581-587.

7 Hole DJ, Watt GC, Davey-Smith G, et al. Impaired lung function and mortality risk in men and women: findings from the Renfrew and Paisley prospective population study. BMJ 1996; 313: 711-715.

8 Lum S, Hoo AF, Hulskamp G, et al. Potential misinterpretation of infant lung function unless prospective healthy controls are studied. Pediatr Pulmonol 2010; [Epub ahead of print DOI: 10.1002/ppul.21255].
9 Frey U, Stocks J, Coates A, et al. Specifications for equipment used for infant pulmonary function testing. ERS/ATS Task Force on Standards for Infant Respiratory Function Testing. European Respiratory Society/ American Thoracic Society. Eur Respir J 2000; 16: 731-740.

10 Frey U, Stocks J, Sly P, et al. Specification for signal processing and data handling used for infant pulmonary function testing. ERS/ ATS Task Force on Standards for Infant Respiratory Function Testing. European Respiratory Society/American Thoracic Society. Eur Respir J 2000; 16: 1016-1022.

11 Bates JH, Schmalisch G, Filbrun D, et al. Tidal breath analysis for infant pulmonary function testing. ERS/ATS Task Force on Standards for Infant Respiratory Function Testing. European Respiratory Society/American Thoracic Society. Eur Respir J 2000; 16: 1180-1192.

12 Baldwin DN, Pillow JJ, Stocks J, et al. Lung-function tests in neonates and infants with chronic lung disease: tidal breathing and respiratory control. Pediatr Pulmonol 2006; 41: 391-419.

13 Baldwin DN, Suki B, Pillow JJ, et al. Effect of sighs on breathing memory and dynamics in healthy infants. J Appl Physiol 2004; 97: 1830-1839.

14 Cernelc M, Suki B, Reinmann B, et al. Correlation properties of tidal volume and end-tidal $\mathrm{O}_{2}$ and $\mathrm{CO}_{2}$ concentrations in healthy infants. J Appl Physiol 2002; 92: 1817-1827.

15 Frey U, Kuehni C, Roiha H, et al. Maternal atopic disease modifies effects of prenatal risk factors on exhaled nitric oxide in infants. Am J Respir Crit Care Med 2004; 170: 260-265.

16 Latzin P, Kuehni CE, Baldwin DN, et al. Elevated exhaled nitric oxide in newborns of atopic mothers precedes respiratory symptoms. Am J Respir Crit Care Med 2006; 174: 1292-1298.

17 Latzin P, Roth S, Thamrin C, et al. Lung volume, breathing pattern and ventilation inhomogeneity in preterm and term infants. PLoS One 2009; 4: e4635.

18 Latzin P, Sauteur L, Thamrin C, et al. Optimized temperature and deadspace correction improve analysis of multiple breath washout measurements by ultrasonic flowmeter in infants. Pediatr Pulmonol 2007; 42: 888-897.

19 Riedel T, Kyburz M, Latzin $\mathrm{P}$, et al. Regional and overall ventilation inhomogeneities in preterm and term-born infants. Intensive Care Med 2009; 35: 144-151.

20 Schibler A, Hall GL, Businger F, et al. Measurement of lung volume and ventilation distribution with an ultrasonic flow meter in healthy infants. Eur Respir J 2002; 20: 912-918.

21 Schibler A, Schneider M, Frey U, et al. Moment ratio analysis of multiple breath nitrogen washout in infants with lung disease. Eur Respir J 2000; 15: 1094-1101.

22 Strippoli MP, Silverman M, Michel G, et al. A parent-completed respiratory questionnaire for 1-year-old children: repeatability. Arch Dis Child 2007; 92: 861-865.

23 Kuehni CE, Brooke AM, Strippoli MP, et al. Cohort profile: the Leicester respiratory cohorts. Int J Epidemiol 2007; 36: 977-985.

24 Prechtl HF. The behavioural states of the newborn infant (a review). Brain Res 1974; 76: 185-212.

25 American Thoracic Society, European Respiratory Society. ATS/ ERS recommendations for standardized procedures for the online and offline measurement of exhaled lower respiratory nitric oxide and nasal nitric oxide, 2005. Am J Respir Crit Care Med 2005; 171: 912-930.

26 Haland G, Carlsen KC, Sandvik L, et al. Reduced lung function at birth and the risk of asthma at 10 years of age. N Engl J Med 2006; 355: 1682-1689.

27 Hall GL, Reinmann B, Wildhaber JH, et al. Tidal exhaled nitric oxide in healthy, unsedated newborn infants with prenatal tobacco exposure. J Appl Physiol 2002; 92: 59-66.

28 Hall GL, Wildhaber JH, Cernelc $M$, et al. Evaluation of the interrupter technique in healthy, unsedated infants. Eur Respir J 2001; 18: 982-988. 
29 Beydon N. Interrupter resistance: what's feasible? Paediatr Respir Rev 2006; 7: Suppl. 1, S5-S7.

30 Stanojevic S, Wade A, Stocks J, et al. Reference ranges for spirometry across all ages: a new approach. Am J Respir Crit Care Med 2008; 177: 253-260.

31 Stocks J, Henschen M, Hoo AF, et al. Influence of ethnicity and gender on airway function in preterm infants. Am J Respir Crit Care Med 1997; 156: 1855-1862.

32 Latzin P, Roosli M, Huss A, et al. Air pollution during pregnancy and lung function in newborns: a birth cohort study. Eur Respir J 2009; 33: 594-603.

33 Lodrup Carlsen KC, Magnus P, Carlsen KH. Lung function by tidal breathing in awake healthy newborn infants. Eur Respir J 1994; 7: 1660-1668.

34 Stocks J, Dezateux CA, Jackson EA, et al. Analysis of tidal breathing parameters in infancy: how variable is TPTEF:TE? Am J Respir Crit Care Med 1994; 150: 1347-1354.

35 Yuksel B, Greenough A, Giffin F, et al. Tidal breathing parameters in the first week of life and subsequent cough and wheeze. Thorax 1996; 51: 815-818.

36 Piippo-Savolainen E, Remes S, Kannisto S, et al. Early predictors for adult asthma and lung function abnormalities in infants hospitalized for bronchiolitis: a prospective 18- to 20-year followup. Allergy Asthma Proc 2006; 27: 341-349.

37 Cook DG, Strachan DP. Health effects of passive smoking - 10: Summary of effects of parental smoking on the respiratory health of children and implications for research. Thorax 1999; 54: 357-366.

38 Stick SM, Burton PR, Gurrin L, et al. Effects of maternal smoking during pregnancy and a family history of asthma on respiratory function in newborn infants. Lancet 1996; 348: 1060-1064.

39 Lodrup Carlsen KC, Jaakkola JJ, Nafstad P, et al. In utero exposure to cigarette smoking influences lung function at birth. Eur Respir J 1997; 10: 1774-1779.

40 Holmen TL, Barrett-Connor E, Clausen J, et al. Gender differences in the impact of adolescent smoking on lung function and respiratory symptoms. the Nord-Trondelag Health Study, Norway, 1995-1997. Respir Med 2002; 96: 796-804.

41 Tager IB, Ngo L, Hanrahan JP. Maternal smoking during pregnancy. Effects on lung function during the first 18 months of life. Am J Respir Crit Care Med 1995; 152: 977-983.
42 Murdzoska J, Devadason SG, Khoo SK, et al. In utero smoke exposure and role of maternal and infant glutathione S-transferase genes on airway responsiveness and lung function in infancy. Am J Respir Crit Care Med, 181: 64-71.

43 Lødrup-Carlsen KC, Carlsen KH. Lung function in awake healthy infants: the first five days of life. Eur Respir J 1993; 6: 1496-1500.

44 Jain L, Dudell GG. Respiratory transition in infants delivered by cesarean section. Semin Perinatol 2006; 30: 296-304.

45 Gabriele C, de Benedictis FM, de Jongste JC. Exhaled nitric oxide measurements in the first 2 years of life: methodological issues, clinical and epidemiological applications. Ital J Pediatr 2009; 35: 21.

46 Wildhaber JH, Hall GL, Stick SM. Measurements of exhaled nitric oxide with the single-breath technique and positive expiratory pressure in infants. Am J Respir Crit Care Med 1999; 159: 74-78.

47 Chawes BL, Buchvald F, Bischoff AL, et al. Elevated exhaled nitric oxide in high-risk neonates precedes transient early but not persistent wheeze. Am J Respir Crit Care Med 2010; 182: 138-142.

48 Gabriele C, van der Wiel EC, Nieuwhof EM, et al. Methodological aspects of exhaled nitric oxide measurements in infants. Pediatr Allergy Immunol 2007; 18: 36-41.

49 Williams O, Rafferty GF, Hannam S, et al. Nasal and lower airway levels of nitric oxide in prematurely born infants. Early Hum Dev 2003; 72: 67-73.

50 Franklin PJ, Turner SW, Mutch RC, et al. Measuring exhaled nitric oxide in infants during tidal breathing: methodological issues. Pediatr Pulmonol 2004; 37: 24-30.

51 Ratjen F, Kavuk I, Gartig S, et al. Airway nitric oxide in infants with acute wheezy bronchitis. Pediatr Allergy Immunol 2000; 11: 230-235.

52 Robinson PD, Goldman MD, Gustafsson PM. Inert gas washout: theoretical background and clinical utility in respiratory disease. Respiration 2009; 78: 339-355.

53 Hulskamp G, Lum S, Stocks J, et al. Association of prematurity, lung disease and body size with lung volume and ventilation inhomogeneity in unsedated neonates: a multicentre study. Thorax 2009; 64: 240-245.

54 Chavasse RJ, Bastian-Lee Y, Seddon P. Comparison of resistance measured by the interrupter technique and by passive mechanics in sedated infants. Eur Respir J 2001; 18: 330-334.

55 Lanteri CJ, Sly PD. Changes in respiratory mechanics with age. J Appl Physiol 1993; 74: 369-378. 